\title{
A Genetic Linkage Map of the House Musk Shrew, Suncus murinus, Constructed with PCR-Based and RFLP Markers
}

\author{
Samuel ADJEI ${ }^{1)}$, Akira SATO'), Takahiro NAGASE ${ }^{2)}$, Kazumi MATSUBARA ${ }^{3)}$, \\ Yoichi MATSUDA ${ }^{3)}$, Takao NAMIKAWA ${ }^{1)}$, and Akira ISHIKAWA ${ }^{1)}$ \\ 1)Laboratory of Animal Genetics, Department of Applied Molecular Biosciences, Graduate School of \\ Bioagricultural Sciences, Nagoya University, Nagoya, Aichi 464-8601, 2)Department of Human \\ Genome Research, Kazusa DNA Research Institute, Kisazaru, Chiba 292-0818, and \\ ${ }^{3)}$ Laboratory of Cytogenetics, Division of Bioscience, Graduate School of Environmental \\ Earth Science, Hokkaido University, Sapporo 060-0810, Japan
}

\begin{abstract}
A genetic linkage map for Suncus murinus was previously constructed with 11 marker loci. In this study, we developed 172 new microsatellite and three RFLP markers, and re-constructed a new framework map by combining all markers. The new map comprises 42 markers that are distributed into 12 linkage groups, two of which are assigned to chromosomes, and spans $403.5 \mathrm{cM}$ with an average inter-marker distance of $13.5 \mathrm{cM}$.
\end{abstract}

Key words: linkage map, microsatellite marker, RFLP marker

The establishment of a genetic map provides the foundation for the chromosomal localization of heritable characteristics, which ultimately may lead to the identification of genes underlying phenotypes of interest. With the advancement of molecular biology, new types of molecular genetic markers have been developed. These markers are classified into three types, type I markers (functional genes), type II markers (microsatellite or anonymous DNA sequences) and type III bi-allelic SNPs [22], and they have been used extensively to saturate the genetic maps of various species [23]. Before the present study, the genetic linkage map of the house musk shrew, Suncus murinus (Order Insectivora), comprised 11 loci including seven comparative anchor tagged sequences (CATS), and three microsatellite and one behavioral mutant genes $[1,2]$. In spite of the paucity of markers,
S. murinus represents an important laboratory species for several reasons. Laboratory strains have been established from wild S. murinus trapped in different localities in Asia [7, 8, 21, 24, 25, 32], and mutant stocks showing morphological and biochemical variants have been reported [9, 10, 26-28,33]. Effects of various emetic and anti-emetic drugs have been studied in this species, because it is one of the few mammalian species that vomit in response to emetic drugs [36]. Other areas of potential use include motion sickness [37], female behavioral endocrinology [30], carcinogenesis [34], nutritional regulation of reproduction [32], periodontal disease [31], and behavioral studies in comparative psychology and related fields [35]. Despite these many benefits of $S$. murinus as a non-rodent model, genetic map information as well as other aspects of genome

(Received 30 May 2007 / Accepted 14 September 2007)

Address corresponding: A. Ishikawa, Laboratory of Animal Genetics, Department of Applied Molecular Biosciences, Graduate School of Bioagricultural Sciences, Nagoya University, Furo-cho, Chikusa-ku, Nagoya, Aichi 464-8601, Japan 
analysis clearly lags behind other biomedical model species. Here, we report the development of new microsatellite and RFLP markers and the construction of a framework linkage map that integrates these markers into the linkage map previously reported $[1,2]$.

To isolate microsatellite DNA from the genome of $S$. murinus, a biotin/streptavidin technique for capturing microsatellite repeats [4] was used with slight modifications. Briefly, $5 \mu \mathrm{g}$ of genomic DNA extracted from the kidney of a single male of the TKU strain (an inbred strain, $\mathrm{F}_{21}$ ) [21], was digested separately with $R s a \mathrm{I}$ and Hae III restriction enzymes. DNA fragments were ligated to commercially synthesized SuperSNX24 linkers (Rikaken Co. Ltd., Nagoya, Japan) and the ligation products were amplified by PCR using the forward SuperSNX24 linker as a primer. The resultant PCR product was denatured at $95^{\circ} \mathrm{C}$ and hybridized to commercially synthesized 3'-biotinylated (AG) ${ }_{12}$ and (TG) $)_{12}$ oligonucleotides (Rikaken Co. Ltd., Nagoya, Japan) overnight at $52.6^{\circ} \mathrm{C}$ and $64.4^{\circ} \mathrm{C}$, respectively. Microsatellite-containing fragments were selectively separated (from the remaining DNA) using streptavidin magnesphere paramagnetic particles (Promega Corp., Tokyo, Japan) prepared according to the manufacturer's instruction. The DNA fragments containing microsatellites were eluted as single strands and the second strand was regenerated by PCR with the forward SuperSNX24 linker as the primer. The PCR products were cloned into pGEM-T Easy vector system II (Promega Corp., Tokyo, Japan) and transformed into Escherichia coli competent cells JM109 (Promega Corp., Tokyo, Japan). Out of a total of 2,000 recombinant clones obtained and screened by PIMA [16], 1,200 clones were selected and sequenced using an ABI PRISM 3130 genetic analyzer (Applied Biosystems, Tokyo, Japan) with a BigDye terminator cycle sequencing kit, version 3.1 (Applied Biosystems, Tokyo, Japan). Sequences were screened against each other using the DNASIS software, version 3.2 (Hitachi Software Engineering Co. Ltd., Tokyo, Japan), to identify duplicates, resulting in complete and high quality sequences for 1,076 clones. Of these, 672 clones (62.5\%) contained microsatellite sequences. Out of the 672 clones, 438 were inappropriate for primer design because 59 were duplicates, 52 had repeat lengths less than $5 \mathrm{bp}$, and 327 had no flanking sequence or the flanking se- quences which were either too short or had several repetitive elements. Primer pairs were finally designed for 234 clones using the web-based software FASTPCR [12], synthesized commercially (Star Oligo, Rikaken Co. Ltd., Nagoya, Japan) and tested for PCR amplification using genomic DNA from the TKU strain. Electrophoresis was performed on $3.5 \%$ agarose or $6.0 \%$ polyacrylamide gels.

A total of 172 primer pairs (i.e. $73.5 \%$ of designed primers) successfully generated single products of size ranging from $98 \mathrm{bp}$ to $570 \mathrm{bp}$. The remaining 62 failed to generate any product and were, consequently, excluded from later analysis. The TKU strain DNA sequences of the clones, from which the 172 primer pairs were developed, were submitted to the DDBJ/EMBL/ GenBank nucleotide sequence databases and have been assigned the accession numbers AB276109, AB277375 to AB277434 and AB277436 to AB277546. The profiles of the microsatellite markers, which include accession number, primer sequence, repeat array, PCR conditions, PCR product size, etc. have been deposited at the Nagoya University repository (URL: http://ir.nul.nagoya-u.ac.jp/ dspace/handle/2237/7581).

To assess the suitability of the 172 microsatellite markers in linkage studies, we used the $\mathrm{F}_{2}$ mapping population constructed in a previous study [2]. The $\mathrm{F}_{2}$ population was constructed by mating four sires of the BAN- $k c$, oeb mutant strain derived from wild individuals captured in Bangladesh [7, 9, 10] with seven dams of the WZ strain derived from wild individuals captured in Japan [27]. The resultant $15 \mathrm{~F}_{1}$ progeny were intercrossed to produce $77 \mathrm{~F}_{2}$ individuals in 20 families [2]. The PCR product of the primer pairs was verified in each of the two grandparental strains and the $\mathrm{F}_{1}$ of the mapping population. Fifty-eight primer pairs amplified products with clearly distinguishable alleles ranging from two to four (see URL: http://ir.nul.nagoya-u.ac. $\mathrm{jp} / \mathrm{dspace} / \mathrm{handle} / 2237 / 7581$ ). Of the remaining primer pairs, 96 generated a single allele while 18 generated a product with several bands that were either non-specific or the inheritance pattern was uninterpretable. Despite the monomorphic nature observed in this study, these 96 markers may be useful in population and other genetic studies of S. murinus, because successful PCR amplification was achieved in the three strains (TKU, BAN-kc,oeb 
and WZ). Their utility in these studies will complement work already done with mitochondria DNA $[15,39,40]$, biochemical variants [33], morphometric parameters [11] and vitamin D binding protein [6]. All the 58 loci with clear alleles exhibited the co-dominant mode of inheritance. For some of the 58 loci, however, heterozygous grandparents shared alleles of the same sizes between the two strains. In families exhibiting these segregating alleles, the $\mathrm{F}_{2}$ descendants were not genotyped because the parental origin of these alleles could not be traced. As a result, 18 of the 58 loci had no $\mathrm{F}_{2}$ individuals in which they could be genotyped. Ultimately, 40 loci were used in linkage studies for $\mathrm{F}_{2}$ individuals ranging from 6 to 77 (Table 1).

RFLP analyses were conducted with standard methods using 29 of 51 human cDNA clones previously localized on S. murinus chromosomes by fluorescence in situ hybridization (FISH) [17]. The 29 clones, selected to cover as many regions of $S$. murinus chromosomes as possible, included $A B C B 1, A C A C A, A C E, A P 2 B 1, A T$ P2A2, CBX5, CSK, ERCC2, EWSR1, FLII, HDLBP, HEMI, HMGCR, HSPAIB, IARS, IDUA, LIGI, MAX, MKI67, MYH9, PTPN11, PTPN13, PML, RCC1, RFC1, RPS6KA1, TAP2, TFRC and XRCC6. A total of eight of the restriction endonucleases (Apa I, Bgl II, BamH I, Dra I, EcoR I, Hind III, Kpn I, Pst I and Xba I) were used to digest approximately $10 \mu \mathrm{g}$ of genomic DNA which was then separated on $0.8 \%$ Seakam GTG Agarose (Cambrex Bioscience Rockland Inc., Rockland, ME, USA) at $18-22 \mathrm{~V} / \mathrm{cm}$ for $15-17 \mathrm{~h}$ by gel electrophoresis. Of the 29 clones screened for RFLPs between the two grandparental strains, inter-strain polymorphisms with adequate hybridization signals were observed in three clones, FLII, MAX and PTPNII (Table 2). The remaining 26 clones showed no, very weak and/or multiple hybridization signals that were not heritable, hence they were discarded. The segregation of FLII and MAX in the $\mathrm{F}_{2}$ population followed the co-dominant fashion while PTPN11 segregated in the dominant fashion (Table 2 ). Except for one $F_{1}$ female with an unclear hybridization signal for FLII, all others were adequate for genotyping in the $\mathrm{F}_{2}$ population.

Prior to linkage analysis, a chi-square test was performed on the 43 polymorphic markers (i.e. 40 microsatellites and three RFLPs) genotyped in the $\mathrm{F}_{2}$ families
Table 1. Goodness-of-fit test results of 40 microsatellite markers genotyped in the $\mathrm{F}_{2}$ mapping population derived from an intercross between BAN-kc,oeb $(\mathrm{B} / \mathrm{B})$ and $\mathrm{WZ}$ (W/W) mutant strains of the house musk shrew, Suncus murinus

\begin{tabular}{|c|c|c|c|c|c|}
\hline \multirow[t]{2}{*}{ Locus } & \multirow[t]{2}{*}{$\mathrm{n}^{\mathrm{a}}$} & \multicolumn{3}{|c|}{ Number of observed genotypes } & \multirow[t]{2}{*}{$\chi^{2}$} \\
\hline & & $\mathrm{W} / \mathrm{W}$ & $\mathrm{B} / \mathrm{W}$ & $\mathrm{B} / \mathrm{B}$ & \\
\hline$N G A 12$ & 77 & 23 & 33 & 21 & 1.68 \\
\hline NGA18 & 77 & 18 & 40 & 19 & 1.14 \\
\hline NGA19 & 50 & 16 & 24 & 10 & 0.12 \\
\hline$N G A 20$ & 73 & 17 & 46 & 10 & $6.29^{b}$ \\
\hline$N G A 21$ & 57 & 17 & 27 & 13 & 0.72 \\
\hline$N G A 24$ & 77 & 23 & 32 & 22 & 2.22 \\
\hline$N G A 31$ & 77 & 18 & 47 & 12 & 4.69 \\
\hline$N G A 33$ & 9 & 2 & 5 & 2 & $(-)^{c}$ \\
\hline NGA38 & 77 & 20 & 39 & 18 & 0.12 \\
\hline NGA39 & 43 & 9 & 22 & 12 & 0.44 \\
\hline$N G A 43$ & 9 & 2 & 5 & 2 & $(-)^{c}$ \\
\hline$N G A 46$ & 38 & 4 & 24 & 10 & 4.53 \\
\hline NGA51 & 77 & 22 & 36 & 19 & 0.64 \\
\hline$N G A 55$ & 35 & 6 & 19 & 10 & 1.19 \\
\hline NGA56 & 56 & 17 & 27 & 12 & 0.96 \\
\hline$N G A 57$ & 72 & 26 & 26 & 20 & $6.56^{\mathrm{b}}$ \\
\hline NGA59 & 75 & 18 & 42 & 15 & 1.33 \\
\hline NGA66 & 11 & 1 & 8 & 2 & $(-)^{c}$ \\
\hline$N G A 67$ & 77 & 17 & 41 & 19 & 0.43 \\
\hline$N G A 76$ & 76 & 24 & 38 & 14 & 2.63 \\
\hline NGA87 & 67 & 16 & 36 & 15 & 0.40 \\
\hline NGA93 & 77 & 20 & 39 & 18 & 0.12 \\
\hline NGA94 & 77 & 16 & 40 & 21 & 0.77 \\
\hline NGA95 & 36 & 7 & 21 & 8 & 1.69 \\
\hline NGA96 & 24 & 8 & 12 & 4 & 1.33 \\
\hline NGA97 & 77 & 24 & 38 & 15 & 2.12 \\
\hline NGA102 & 77 & 15 & 42 & 20 & 1.29 \\
\hline NGA103 & 46 & 16 & 26 & 4 & $7.04^{\mathrm{b}}$ \\
\hline NGA114 & 76 & 17 & 37 & 22 & 0.71 \\
\hline$N G A 118$ & 47 & 12 & 25 & 10 & 0.36 \\
\hline NGA119 & 76 & 18 & 40 & 18 & 0.21 \\
\hline NGA120 & 6 & 2 & 3 & 1 & $(-)^{c}$ \\
\hline NGA130 & 76 & 23 & 41 & 12 & 3.66 \\
\hline NGA131 & 73 & 15 & 41 & 17 & 1.22 \\
\hline$N G A 145$ & 30 & 5 & 13 & 12 & 3.80 \\
\hline NGA146 & 48 & 16 & 19 & 13 & 2.46 \\
\hline NGA155 & 77 & 19 & 30 & 28 & 5.86 \\
\hline$N G A 161$ & 30 & 8 & 13 & 9 & 0.60 \\
\hline NGA163 & 77 & 19 & 35 & 23 & 1.11 \\
\hline NGA179 & 74 & 18 & 41 & 15 & 1.12 \\
\hline
\end{tabular}

aNumber of $\mathrm{F}_{2}$ individuals that could be genotyped (see text for details). bDeviated significantly from Mendelian expectations at $P<0.05$ (d.f.=2). cMultinomial test was used to check for Mendelian deviations from expected ratios.

to determine whether genotypic ratios differed from expected Mendelian ratios. For loci whose genotyping was performed for the $\mathrm{F}_{2}$ population less than 20 indi- 
Table 2. The RFLP markers that were polymorphic between BAN-kc,oeb (B/B) and WZ (W/W) mutant strains of the house musk shrew, Suncus murinus

\begin{tabular}{|c|c|c|c|c|c|c|c|c|c|c|c|}
\hline \multirow{2}{*}{$\begin{array}{l}\text { Gene } \\
\text { symbol }\end{array}$} & \multirow{2}{*}{$\begin{array}{l}\text { S. murinus } \\
\text { cytogenetic } \\
\text { location }^{\mathrm{a}}\end{array}$} & \multirow{2}{*}{$\begin{array}{l}\text { Restriction } \\
\text { enzymes }\end{array}$} & \multicolumn{3}{|c|}{ Fragment size $(\mathrm{kb})$} & \multirow{2}{*}{$\begin{array}{l}\text { Expected } \\
\text { mode of } \\
\text { inheritance }\end{array}$} & \multirow{2}{*}{$\begin{array}{l}\text { No. of } F_{2} \\
\text { individuals } \\
\text { genotyped }\end{array}$} & \multicolumn{3}{|c|}{ Observed genotypes } & \multirow[t]{2}{*}{$\chi^{2}$} \\
\hline & & & Common & BAN & WZ & & & $\mathrm{B} / \mathrm{B}$ & $\mathrm{B} / \mathrm{W}$ & $\mathrm{W} / \mathrm{W}$ & \\
\hline FLII & $19 \mathrm{q} 2.1-\mathrm{q} 2.2$ & BamH I & 1.2 & 5.8 & 7.0 & Co-dominant & 67 & 16 & 21 & 30 & $15.18^{\mathrm{b}}$ \\
\hline$M A X$ & $10 \mathrm{q} 5.3-\mathrm{q} 5.5$ & Pst I & $10.5,1.5$ & 3.6 & 4.1 & Co-dominant & 71 & 12 & 46 & 13 & $6.24^{\mathrm{b}}$ \\
\hline PTPN11 & $13 q 1.6$ & BamH I & No band & 2.0 & No band & Dominant & 77 & \multicolumn{2}{|c|}{$57^{\mathrm{c}}$} & 20 & 0.04 \\
\hline
\end{tabular}

${ }^{a}$ Mapped by fluorescence in situ hybridization (FISH) [17]. ' ${ }^{b}$ Significantly different from Mendelian expected ratios at $P<0.05$. ${ }^{\mathrm{B}} \mathrm{B} / \mathrm{B}$ and $\mathrm{B} / \mathrm{W}$ genotypes were not distinguishable.

viduals, the multinomial test was used. Five markers (NGA20, NGA57, NGA103, FLII and MAX) exhibited significant segregation distortions at $P<0.05$. However, these markers showed no difference in linkage and marker order before and after the G-statistic for independence was applied. All other markers fell within the expected Mendelian ratios at $P>0.05$ (see Tables 1 and 2).

In all, a total of 65 loci were employed in linkage analysis with the Map Manager QTXb20 program [18]. Significant linkages (lod score $\geq 3.0$ ) were identified for 41 markers, which were assigned to 11 linkage groups. Apart from the mutant locus, $k c$, which showed a probable linkage to $N G A 114$ (LOD=2.4), all the remaining 21 loci showed no significant linkage to other markers on the map. The length of individual linkage groups varied from zero to $66.6 \mathrm{cM}$ and the number of markers per group ranged from one to six (Fig. 1). The map spanned $403.5 \mathrm{cM}$ with an average inter-marker distance of $13.5 \mathrm{cM}$.

One locus (FLII), previously localized to $S$. murinus chromosome 19q2.1-q2.2 by FISH [17], was linked with CYP1A2 (LOD=7.4). This group was, consequently, assigned to $S$. murinus chromosome 19 . The assignment of CYP1A2 to chromosome 19 was also supported by a comparative cytogenetic analysis. Localized with FLII in the same region of S.murinus chromosome 19 are the two loci, PML (19q1.4-q1.6) and CSK (19q1.3-q1.4). Matsubara et al. [17] showed that the chromosomal region containing these two loci (CSK and $P M L$ ) is conserved among S. murinus (chromosome 19q1.3-1.6 containing CSK and PML), Homo sapiens (chromosome 15q22-q25 containing $C S K, P M L$ and $C Y P 1 A 2$ ), and Mus musculus (chromosome 9, which also contains Csk,
Pml, and Cyp 1 a2). Searching the Rat Genome Database (http://ratmap.gen.gu.se/) also showed that the three genes, Csk, Pml, and Cypla2, are localized in the same region on Rat norveticus chromosome 8 (i.e. region q24).

Additionally, the locus NGA184 (GHR) was assigned to $S$. murinus chromosome $\mathrm{X}$ because the segregation pattern observed was based on the X-linked mode of inheritance (i.e. 1:1 ratio in all $\mathrm{F}_{2}$ males). Also, the $S$. murinus amplified sequence of this marker matched BAC clones from $\mathrm{X}$ chromosomes of human, mouse and rat. The name NGA184 (GHR) was consequently changed to DXNGA184 following the standardized rules and guidelines for nomenclature of anonymous DNA markers in the mouse and rat (http://informatics.jax.org/mgihome/ nomen).

We estimated the genetic linkage map length of the $S$. murinus genome using the equation $\mathrm{G}=\mathrm{N}(\mathrm{N}-1) \mathrm{X} / \mathrm{K}$, described by Hulbert et al. [5], where G is the genome map length, $\mathrm{N}$ is the number of informative (or typed) markers, $\mathrm{X}$ is the average inter-marker distance and $\mathrm{K}$ is the number of informative markers (i.e. linked to another marker) at or above the selected LOD threshold. The estimated genome map length of S. murinus is approximately $1,400 \mathrm{cM}$ \{i.e. 65(65-1) $13.5 / 41$ \}. This estimated length seems to be compatible with estimates for other mammalian species, which range from 1,398 $\mathrm{cM}$ for the mouse [29] to $>3,500 \mathrm{cM}$ in humans [14], cattle [3,13], and sheep [19]. Given this genetic linkage map length of $1,400 \mathrm{cM}$ and with the current average inter-marker distance of $13.5 \mathrm{cM}$, approximately 100 markers would be needed to cover the entire genome map. With the marker status currently standing at 62 (i.e. excluding the three mutant loci), approximately 50 new 

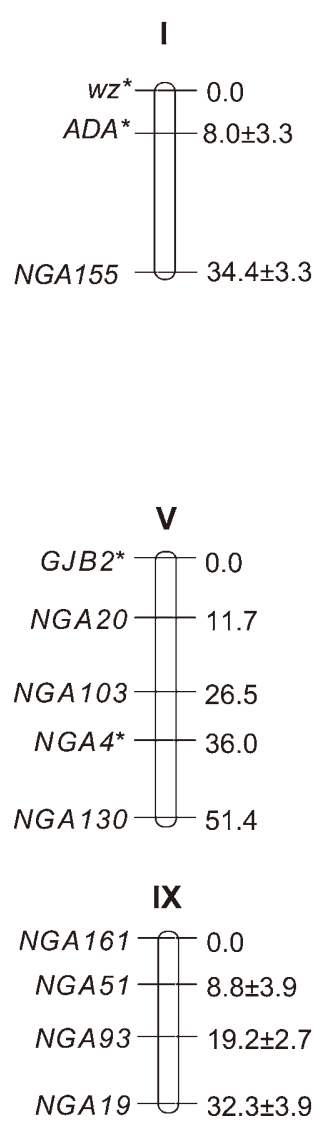

II
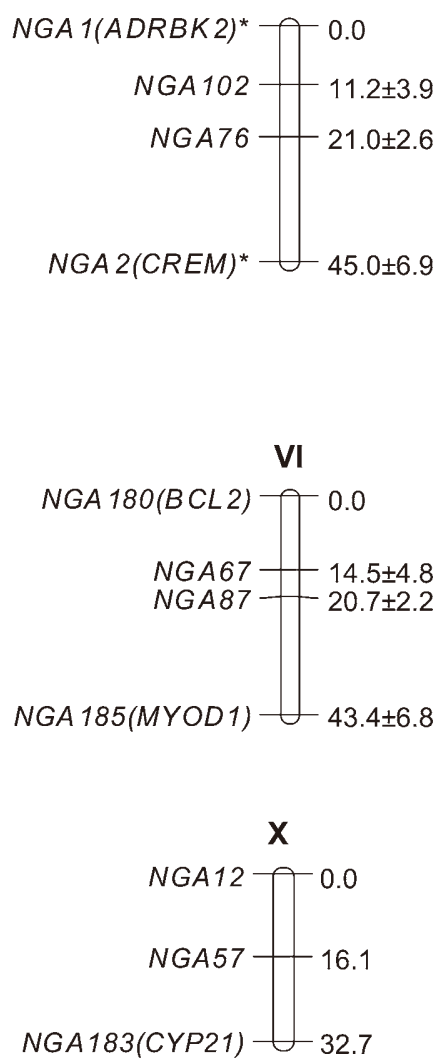

III
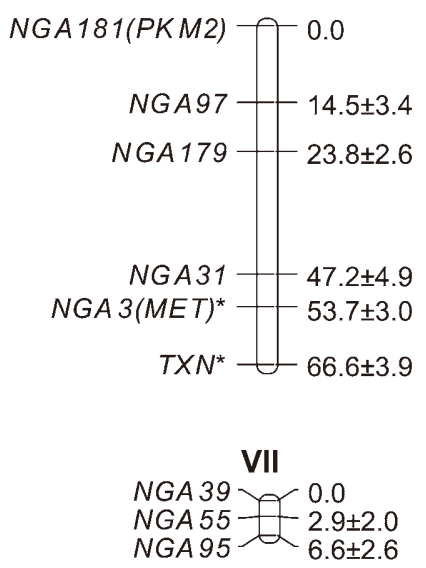

Chr. 19

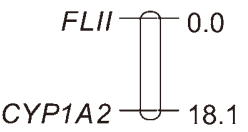

IV

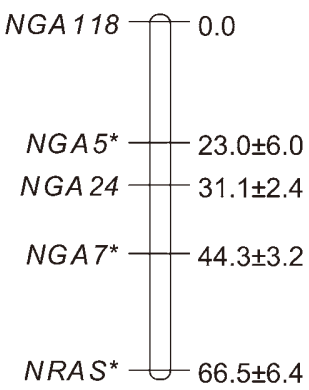

VIII

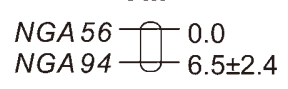

Fig. 1. A genetic linkage map of the house musk shrew, Suncus murinus. The map was constructed with Map Manager QTXb20 [15]. Distances $( \pm \mathrm{SE})$ in $\mathrm{cM}$ were computed with the Kosambi mapping function and the cumulative distances from the top are listed to the right of each linkage group. Markers shown with asterisks were mapped in previous studies [1,2]. The G-statistic for independence was applied to linkage groups V and X, and chromosome 19 (See text for details). Locus names in parenthesis correspond to CATS primer pairs [2]. The S. murinus DNA sequences of these CATS primer pair amplicons did not match the genes from which the primer pairs were originally designed. The map was drawn using the MapChart 2.1 software [38].

polymorphic markers will be required to achieve this target. Whereas the current genetic map provides an important resource for mapping studies in S. murinus, the assignment of our markers on the map to chromosomes will be required to enhance its utility in genetic studies.

In conclusion, we have made available 172 microsatellite markers and have constructed a mixed marker linkage map comprising type I and type II markers. The reproducible nature of the markers makes the linkage map a framework on which additional markers can be incorporated to enhance and resolve the genetic distance of the map and genome coverage of this species. The microsatellite markers developed in this study should be a valuable resource for molecular genetic studies, population genetics, and so on.

\section{Acknowledgment(s)}

We are thankful to the Nagoya University Radioisotope Centre for making their facility available to us. Research grant number 17650119 received by Akira Ishikawa from the Ministry of Education, Culture, Sports and Science \& Technology of Japan supported this study.

\section{References}

1. Adjei, S. and Ishikawa, A. 2007. Exp. Anim. 56: 51-56.

2. Adjei, S., Sato, A., Tanaka, S., Kobayashi, E., Tanaka, K., Namikawa, T., and Ishikawa, A. 2005. Exp. Anim. 54: 173-180.

3. Barendse, W., Vaiman, D., Kemp, S.J., Sugimoto, Y., 
Armitage, S.M., Williams, J.L., Sun, H.S., Eggen, A., Agaba, M., Aleyasin, S.A., Band, M., Bishop, M.D., Buitkamp, J., Byrne, K., Collins, F., Cooper, L., Coppettiers, W., Denys, B., Drinkwater, R.D., Easterday, K., Elduque, C., Ennis, S., Erhardt, G., Ferretti, L., Flavin, N., Gao, Q., Georges, M., Gurung, R., Harlizius, B., Hawkins, G., Hetzel, J., Hirano, T., Hulme, D., Jorgensen, C., Kessler, M., Kirkpatrick, B.W., Konfortov, B., Kostia, S., Kuhn, C., Lenstra, J.A., Leveziel, H., Lewin, B., Leyhe, H.A., Lil, L., Burriel, I.M., McGraw, R.A., Miller, J.R., Moody, D.E., Moore, S.S., Nakane, S., Nijman, I.J., Olsaker, I., Pomp, D., Rando, A., Ron, M., Shalom, A., Teale, A.J., Thieven, U., Urquhart, B.G.D., Vage, D.-I., Van de Weghe, A., Varvio, S., Velmala, R., Vilkki, R., Weikard, J., Woodside, C., Womack, J.E., Zanotti, M., and Zaragoza, P. 1997. Mamm. Genome 8: 21-28.

4. Glenn, T.C. and Schable, N.A. 2005. Meth. Enzymol. 375: 202-222.

5. Hulbert, S.H., Ilott, T.W., Legg, E.J., Lincoln, S.E., Lander, E.S., and Michelmore, R.W. 1988. Genetics 120: 947958.

6. Iseki, R. and Kondo, K. 1984. Anim. Blood Groups Biochem. Genet. 15: 55-61.

7. Ishikawa, A., Tsubota, Y., and Namikawa, T. 1987. Exp. Anim. 36: 253-260.

8. Ishikawa, A., Akadama, I., Namikawa, T., and Oda, S. 1989. Exp. Anim. 38: 231-237.

9. Ishikawa, A., Hirunagi, K., Oda, S., Namikawa, T., and Tomita, T. 1992. Exp. Anim. 42: 203-214.

10. Ishikawa, A., Naito, J., and Namikawa, T. 1998. Exp. Anim. 47: 105-110.

11. Ishikawa, A., Yamagata, T., and Namikawa, T. 1995. Jpn. J. Genet. 70: 57-74.

12. Kalendar, R. 2004. URL: http//www.biocenter.helsinski.fi/ bi/bare1_html/fastpcr.

13. Kappes, S.M., Keele, J.W., Stone, R.T., Mcgraw, R.A., Sonstegard, T.S., Smith, T.P., Lopez-Corrales, N.L., and Beattie, C.W. 1997. Genome Res. 7: 235-249.

14. Kong, A., Gudbjartsson, D., Sainz, J., Jonsdottir, G.M., Gudjosson, S.A., Richardsson, B., Sigurdardottir, S., Barnard, J., Hallbeck, B., Masson, G., Shlien, A., Palsson, S.T., Frigge, M.L., Thorgeirsson, T.E., Gulcher, J.R., and Stefansson, K. 2002. Nat. Genet. 31: 241-247.

15. Kurachi, M., Chau, B.-L., Dang, V.-B., Dorji, T., Yamamoto, Y., Nyunt, M.M., Maeda, Y., Chhum-Phith, L., Namikawa, T., and Yamagata, T. 2007. Biochem. Genet. 45: 165-183.

16. Lunt, D.H., Hutchinson, W.T., and Carvalho, G.R. 1999. Mol. Ecol. 8: 891-894.

17. Matsubara, K., Ishikawa, A., Kuroiwa, A., Nagase, T., Nomura, N., Namikawa, T., and Matsuda, Y. 2001. Cytogenet. Cell Genet. 93: 258-262.

18. Manly, K.F., Cudmore, Jr. R.H., and Meer, J.M. 2001. Mamm. Genome 12: 930-932.

19. Mikawa, S., Akita, T., Hisamatsu, N., Inage, Y., Ito, Y.,
Kobayashi, E., Kusumoto, H., Matsumoto, T., Mikami, H., Minezawa, M., Miyake, M., Shimanuki, S., Sugiyama, C., Uchida, Y., Wada, Y., Yanai, S., and Yasue, H. 1999. Anim. Genet. 30: 407-417.

20. Morton, N.E. 1955. Am. J. Hum. Genet. 7: 277-318.

21. Namikawa, T., Tsubota, Y., Iseki, R., and Matsuda, Y. 1985. pp. 327-334. In: Biology of the laboratory Shrew (Oda, S., Kitoh, J., Ota, K., and Isomura, G. eds.), Japan Scientific Society Press, Tokyo (in Japanese with English abstract).

22. O'Brien, S.J., Menotti-Raymond, M., Murphy, W.J., Nash, W.G., Wienberg, J., Stanyon, R., Copeland, N.G., Jenkins, N.A., Womack, J.E., and Graves, J.A.M. 1999. Science 286: $458-481$.

23. O’Brien, S.J., Womack, J.E., Lyons, L.A., Moore, K.J., Jenkins, N.A., and Copeland, N.J. 1993. Nat. Genet. 3: 103-112.

24. Oda, S. and Kondo, K. 1976. Mamm. Sci. 33: 13-30 (in Japanese).

25. Oda, S., Koyasu, K., and Shretha, K.C. 1992. Ann. Res. Inst. Environ. Med. 43: 239-240 (in Japanese).

26. Ohno, T., Ishikawa, A., and Namikawa, T. 1994. Exp. Anim. 41: 173-179.

27. Ohno, T., Ishikawa, A., Yamagata, T., Namikawa, T., and Tomita, T. 1992. Exp. Anim. 41: 123-129.

28. Ohno, T. and Namikawa, T. 1992. Exp. Anim. 43: 111113.

29. Rhodes, M., Straw, R., Fernando, S., Evans, A., Lacey, T., Dearlove, A., Greystrong, J., Walker, J., Watson, P., Weston, P., Kelly, M., Taylor, D., Gibson, K., Mundy, C., Bourgade, F., Poirier, C., Simon, D., Brunialti, A.L.B., Montagutelli, X., Gu'enet, J.-L., Haynes, A., and Brown, S.D.M. 1998. Genome Res. 8: 531-542.

30. Rissman, E.F. 1990. J. Exp. Zool. Suppl. 4: 207-209.

31. Takata, T., Matsuura, M., Murashima, M., Miyauchi, M., and Mikai, H. 1999. J. Periodontol. 70: 195-200.

32. Temple, J.L. 2004. ILAR J. 45: 25-34.

33. Tsubota, Y. and Namikawa, T. 1988. Exp. Anim. 37: 159164.

34. Tsubura, A., Shikata, N., Oyaizu, T., and Takahashi, H. 1995. Histol. Histopathol. 10: 1047-1055.

35. Tsuji, K.-I., Ishii, K., Matsuo, T., and Kawano, K. 1999. Jpn. J. Anim. Psychol. 49: 1-18.

36. Ueno, S., Matsuki, N., and Saito, H. 1987. Life Sci. 41: 513-581.

37. Ueno, S., Matsuki, N., and Saito, H. 1988. Life Sci. 43: 413-420.

38. Vorrips, R.E. 2002. J. Hered. 93: 77-78.

39. Yamagata, T., Ohishi, K., Faruque, M.O., Masangkay, J.S., Ba-Loc, C., Vu-Binh, D., Mansjoer, S.S., Ikeda, H., and Namikawa, T. 1995. Jpn J. Genet. 70: 321-337.

40. Yamagata, T., Tanaka, Y., Ishikawa, A., Namikawa, T., and Tomita, T. 1990. Biochem. Genet. 28: 185-195. 